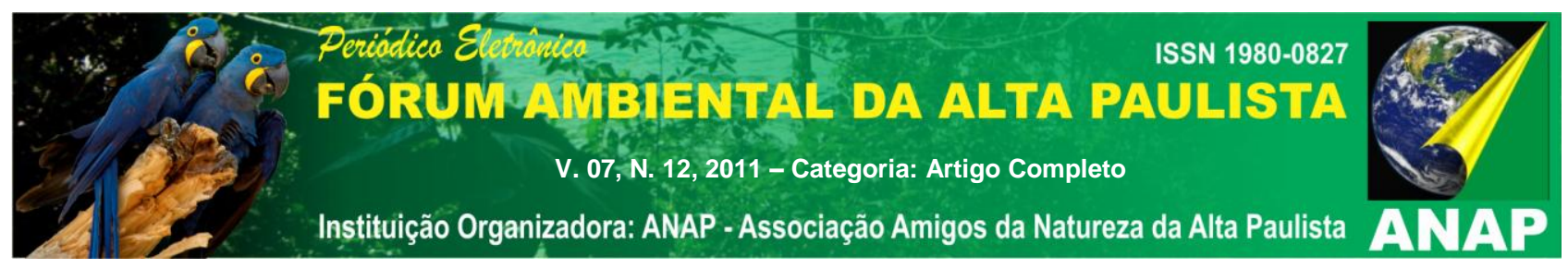

\title{
TEORES ELEVADOS DE MANGANÊS EM AMOSTRAS DE SOLOS
}

Helena Magalhães Prates ${ }^{1}$

Flávio Fernando Manzini²

Lídia Maria de Almeida Plicas ${ }^{3}$

Daniela Correa de Oliveira Lisboa ${ }^{4}$

Resumo: Inúmeros são os trabalhos versando sobre a contaminação de águas e solos por metais potencialmente tóxicos, ou metais pesados. O destaque sempre é dado para chumbo, mercúrio e, mais recentemente, cádmio que, também é, comprovadamente, carcinogênico. Em contrapartida, estudos sobre a toxicidade do manganês são raros devido, provavelmente, ao fato do mesmo ser um metal essencial à vida. Porém, absorvido em doses elevadas pelo organismo, pode provocar uma série de patologias e disfunções, algumas muito graves como déficit intelectual. Nesse trabalho procurou-se avaliar a concentração de manganês em amostras de solos cultivados e não cultivados de várias regiões do Estado de São Paulo. Surpreendentemente, algumas dessas amostras apresentaram teores até cinco vezes mais elevados do que o limite estabelecido como alto pelo Governo do Estado de São Paulo (que é de 5 $\mathrm{mg} / \mathrm{dm}^{3}$ ). A provável fonte desse excesso reside na liberação de produtos de combustão e/ou na forma de aditivos aos combustíveis.

Palavras chave: solos contaminados, metais pesados, manganês

\footnotetext{
${ }^{1}$ Bacharel em Química Ambiental, Instituto de Biociências, Letras e Ciências Exatas, UNESP-SP hel_magalhaes@yahoo.com.br

2 Doutor em Geologia Regional, Instituto de Biociências, Letras e Ciências Exatas, UNESP-SP fmanzini@ibilce.unesp.br

3 Doutora em Físico-Química, Instituto de Biociências, Letras e Ciências Exatas, UNESP-SP plicas@ibilce.unesp.br

${ }^{4}$ Bacharel em Química, Instituto de Biociências, Letras e Ciências Exatas, UNESP-SP

danielac@ibilce.unesp.br
} 


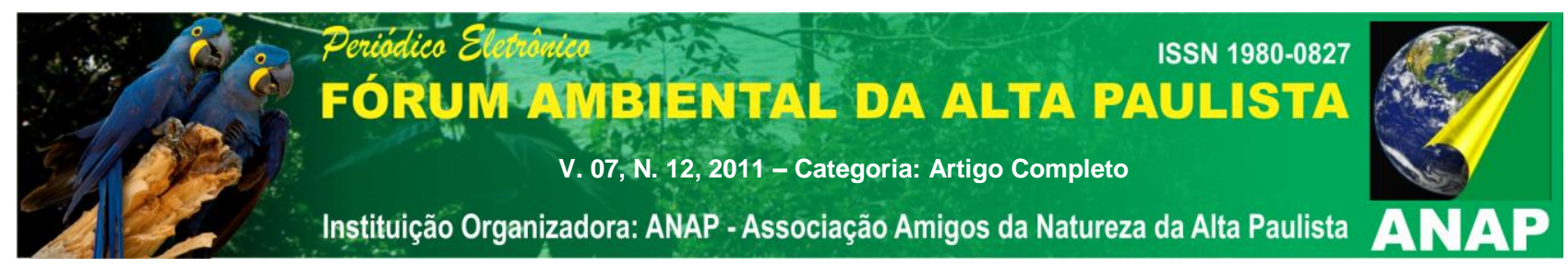

\subsection{INTRODUÇÃO}

O manganês é um elemento químico, de símbolo Mn, com número atômico 25 e sólido em temperatura ambiente. É um metal de transição do grupo 7 da tabela periódica. Como os demais elementos de transição, possui algumas propriedades características: apresenta várias formas e estados de oxidação $(0 \mathrm{a}+7)$ e pode formar vários compostos coloridos e paramagnéticos. É um metal que se apresenta sólido, frágil e quebradiço sendo, facilmente, oxidável. É o terceiro metal mais abundante na crosta terrestre, depois do alumínio e do ferro estando amplamente distribuído (WIKIPÉDIA e MARTINS \& LIMA, 2001 apud MANZINI et al, 2010).

Sua ocorrência nos solos brasileiros é, predominantemente, pedogenética com teores disponíveis que variam de 3 a $190 \mathrm{mg} / \mathrm{dm}^{3}$. Esta concentração ocorre nos horizontes superficiais de solos do Estado de São Paulo. Muito provavelmente, será maior nas camadas mais profundas (CARDOSO et al. 2003 apud MANZINI et al., 2010).

É um elemento natural que se encontra facilmente nas rochas. Apresenta-se em quatro formas alotrópicas: alfa, beta, gama e delta. Não ocorre em sua forma pura. Ocorre combinado com outros elementos como o oxigênio, enxofre e cloro. Estes compostos são sólidos que não se evaporam. Pequenas partículas de pó desse material sólido podem existir suspensas no ar e, além disso, alguns compostos podem dissolver-se na água sendo detectados, por vezes, baixos teores dos mesmos em lagos, riachos e oceanos. $\mathrm{O}$ manganês pode transformar-se de um composto a outro, mas não se degrada e nem desaparece do ambiente. É encontrado em centenas de minerais, embora apenas uma dezena apresente interesse comercial. Destacam-se a: pirolusita $\left(\mathrm{MnO}_{2}\right)$, psilomelano $\left(\mathrm{MnO}_{2} \cdot \mathrm{H}_{2} \mathrm{O}\right)$, manganita $(\mathrm{MnO}(\mathrm{OH}))$, braunita $\left(3 \mathrm{Mn}_{2} \mathrm{O}_{3} \cdot \mathrm{MnSiO}_{3}\right)$, rodonita $\left(\mathrm{MnSiO}_{3}\right)$, rodocrosita $\left(\mathrm{MnCO}_{3}\right)$, hübnerita $\left(\mathrm{MnWO}_{4}\right)$, entre tantos. Também ocorre no leito marinho, na forma de nódulos, onde o conteúdo de manganês oscila entre 15 a 30\%. Há possibilidade de aproveitamento econômico dessa forma de ocorrência. Os compostos de manganês podem ser classificados em orgânicos e inorgânicos. Entre as formas inorgânicas incluem-se as que se encontram nos produtos de combustão no escapamento de automóveis ou caminhões e nos pós que estão presentes na produção de aço ou baterias. As formas orgânicas de manganês são, principalmente, os aditivos para a 


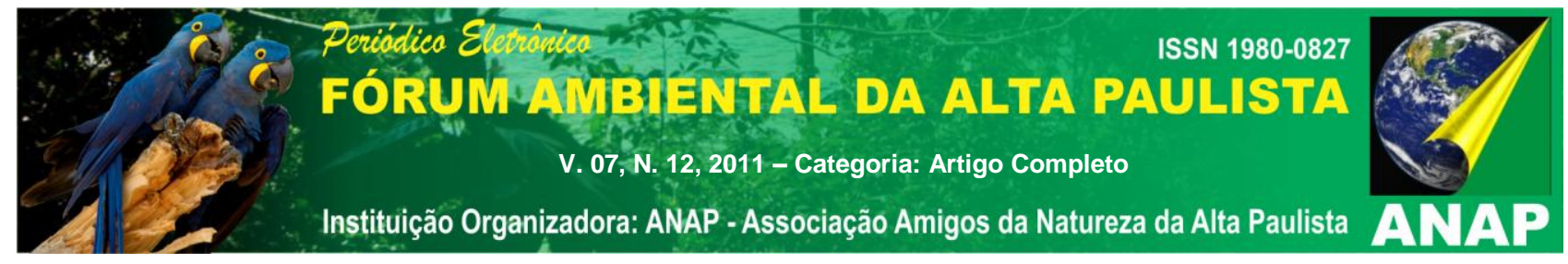

gasolina, para os praguicidas, e um composto usado em hospitais para se diagnosticar alguns tipos de câncer (MARTINS \& LIMA, 2001, WIKIPÉDIA e ATSDR apud MANZINI et al., 2010).

Os seres humanos estão expostos ao manganês nos alimentos, na água que ingerem e no ar que respiram. As crianças amamentadas ingerem manganês presente no leite materno, em fórmulas infantis a base de soja ou em leite de vaca. O manganês é essencial à manutenção da vida. Sua carência, nos humanos, pode causar perda de peso, fragilidade óssea, dermatite, degeneração do ovário ou testículos e náuseas (ATSDR). Seu excesso pode causar dermatite, diminuição do colesterol sérico, diminuição dos fatores coagulantes dependentes da vitamina $\mathrm{K}$, aumento dos níveis sanguíneos de cálcio, fósforo e fosfatase alcalina (podendo este último fator ser indicativo de uma remodelação óssea), infertilidade, diminuição do metabolismo da glucose, diminuição do metabolismo proteico, diminuição do crescimento e distúrbios ao nível do esqueleto, aterosclerose, disfunção pancreática, aumento da pressão sanguínea, redução da função imune, ataxia, deficiência de selênio, depressão da atividade das glândulas mamárias e anormalidades nas mitocôndrias (DAMIÃO \& RAMOS, 2004/2005).

Estudo realizado por Menezes Filho (2009), na Vila de Cotegipe, Município de Simões Filho, no Estado da Bahia, demonstrou que a comunidade se encontra exposta a níveis de concentração elevada de manganês o que tem afetado, em especial, as crianças que apresentam desempenho intelectual deficiente. Existe, ainda, a hipótese de que esta dosagem influencie no desenvolvimento das crianças via transferência maternofetal. Esta situação de contaminação é proporcionada por emissões atmosféricas da Companhia Rio Doce Manganês (RDM), uma metalúrgica de ligas ferro-manganês. Este metal tem uma meia-vida curta, em média 36 dias, que depende da ingestão e da carga corpórea de manganês. No cérebro a meia-vida é consideravelmente mais longa do que no corpo como um todo. Portanto, numa situação de absorção excessiva, o Mn pode se acumular no cérebro. O aumento da concentração de Mn no cérebro pode dar início a danos neuronais, resultando em diminuição no número de neurônios dopaminérgicos. Macacos expostos cronicamente ao Mn através de injeção intravenosa ou por inalação apresentaram significativo decréscimo na função cognitiva e alterações comportamentais compatíveis com transtorno compulsivo. 
Quanto ao manganês liberado por meio de produtos de combustão e/ou na forma de aditivos aos combustíveis (no caso, MMT - Metilciclopentadienil tricarbonil manganês, um aditivo antidetonante da gasolina) não existem relatos. Nesse trabalho foram detectados teores elevados do metal em amostras de solos coletadas, dentre outros, nas proximidades de rodovias e/ou vias públicas de tráfego intenso de veículos que, na ausência de qualquer outra forma de dispersão do mesmo para a atmosfera, com certeza são os responsáveis por esses resultados.

O estudo objetivou:

- avaliar a concentração de manganês, extraído por ácido dietilenotriaminopentacético + trietanolamina (DTPA-TEA), em amostras de solos não cultivados das regiões de Olímpia, São José do Rio Preto, Araçatuba, Monte Alto e Adolfo e cultivados com laranja e cana da região de Mogi Guaçu, expostos a fontes diferentes de concentração do mesmo (combustíveis, fertilizantes, entre outros), uma vez que estudos dessa natureza são escassos;

\subsection{DESENVOLVIMENTO}

\subsubsection{Materiais e metodologias}

\subsubsection{Materiais}

Os materiais utilizados neste projeto foram:

- vidrarias apropriadas e material de filtragem

- reagentes de grau analítico, água destilada

- conjunto de peneiras Bender para granulometria

- pHmetro DIGIMED DM 22

- balança analítica OWA Labor

- mesa agitadora Quimis

- espectrofotômetro de absorção atômica por atomização em chama modelo AA240FS (AAS)

\subsubsection{Metodologias}




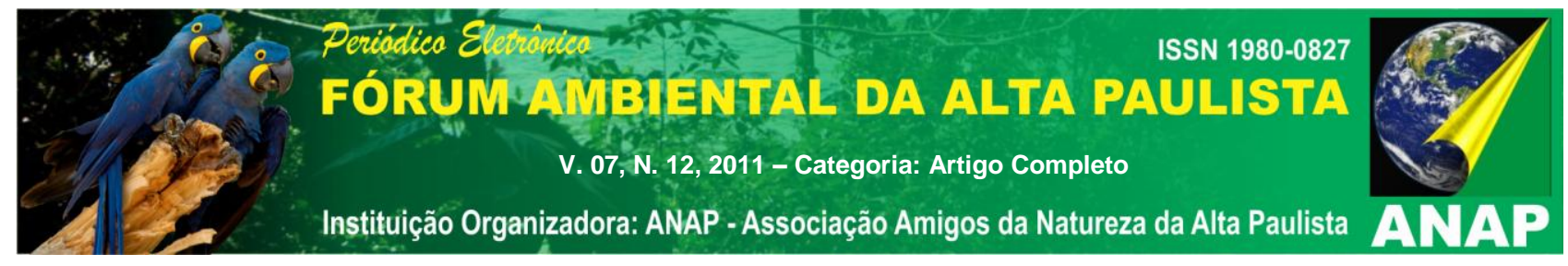

\subsection{Amostragem}

Nesse trabalho foram utilizadas amostras de argissolos, não cultivados, coletadas á beira de rodovias ou de vias públicas, nas regiões das cidades de Olímpia, São José do Rio Preto, Araçatuba, Monte Alto e Adolfo, além de amostras de latossolos cultivados com laranja e cana-de-açúcar da região da cidade de Mogi Guaçu, seguindo a metodologia de coleta proposta por Silva (1999).

Relação das amostras (44 no total):

- amostras de números 1, 3 e 5 e de siglas 2F e 4F: região de Olímpia

- amostras de números 5, 7 e 9 e de siglas $6 \mathrm{~F}, 8 \mathrm{~F}$ e $10 \mathrm{~F}$ e $1 \mathrm{~N}$ a $6 \mathrm{~N}$ : região de São José do Rio Preto

- amostras de números 11, 13 e 15 e de siglas 12F e 14F: região de Araçatuba

- amostras de números 17 e 19 e de siglas 16F, 18F e 20F: região de Monte Alto

- amostras de siglas $7 \mathrm{~N}$ a $14 \mathrm{~N}$ : região de Adolfo

- amostras de números 1 a 5(laranja) e 1 a 5(cana-de-açúcar): região de Mogi Guaçu

\subsection{Determinação de manganês solúvel em DTPA-TEA}

A determinação do teor de manganês extraído por DTPA-TEA foi realizada a partir da metodologia proposta por Camargo et al. (2009), a seguir.

Preparo das soluções de trabalho:

a) Solução de DTPA-TEA a pH 7,3: foram dissolvidos 1,96g de DTPA num béquer com aproximadamente $200 \mathrm{~mL}$ de água destilada. Adicionou-se 13,3 $\mathrm{mL}$ de trietanolamina e, em seguida, $1,47 \mathrm{~g}$ de cloreto de cálcio $\left(\mathrm{CaCl}_{2} \cdot 2 \mathrm{H}_{2} \mathrm{O}\right)$. Transferiu-se para um balão volumétrico de $1 \mathrm{~L}$, completou-se o volume com água destilada e agitou-se, manualmente, até a completa dissolução do sal. Quando necessário, o pH foi corrigido com ácido clorídrico concentrado, até o valor 7,3.

b) Solução-estoque de manganês $(1.000 \mathrm{mg} / \mathrm{L})$ : foram transferidos $3,0765 \mathrm{~g}$ de sulfato manganoso $\left(\mathrm{MnSO}_{4} \cdot \mathrm{H}_{2} \mathrm{O}\right)$ para balão volumétrico de $1 \mathrm{~L}$. Em seguida foram adicionados 5 $\mathrm{mL}$ de ácido sulfúrico concentrado e completou-se o volume com água destilada. 


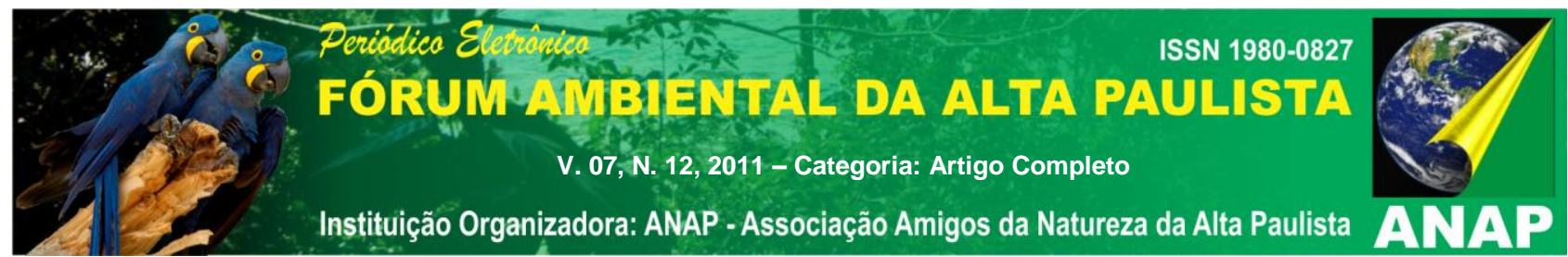

c) Solução intermediária de manganês $(50 \mathrm{mg} / \mathrm{L})$ : foram transferidos $10 \mathrm{~mL}$ da soluçãoestoque de manganês $(1.000 \mathrm{mg} / \mathrm{L})$ para balão volumétrico de $200 \mathrm{~mL}$. Foram acrescentados $5 \mathrm{~mL}$ de solução de ácido clorídrico $6 \mathrm{~mol}^{\mathrm{L}} \mathrm{L}^{-1}$ e completou-se o volume com solução extratora.

Elaboração da curva-padrão:

Inicialmente, foram colocados, em balões volumétricos de $50 \mathrm{~mL}$, os volumes das soluções intermediárias $(0,50 ; 2,00 ; 5,00 ; 10,0 ; 20,0$ e 30,0 mg/L), completando-se com a solução extratora de DTPA-TEA a pH 7,3. Em seguida, foi realizada a leitura em espectrofotômetro de absorção atômica, no comprimento de onda $\lambda=279,5 \mathrm{~nm}$.

Após o preparo das soluções-padrão e da construção da curva-padrão, foram colocados $5 \mathrm{~g}$ de amostra de solo em frasco plástico de $50 \mathrm{~mL}$. Foram, então, adicionados, $10 \mathrm{~mL}$ da solução extratora de DTPA-TEA, e este sistema foi agitado por 2 h. Procedeu-se à filtragem e à análise por AAS. As análises foram realizadas em duplicata.

\subsubsection{RESULTADOS E DISCUSSÕES}

Os gráficos obtidos das curvas-padrão de manganês no solo são ilustrados pelas figuras 1, 2, 3 e 4 .

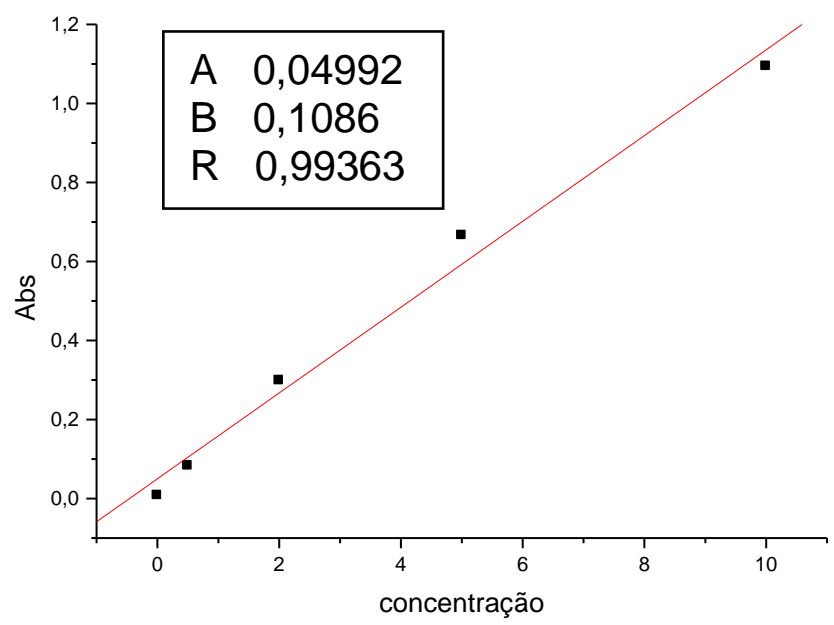

Figura 1. Curva-padrão utilizada para as seguintes amostras: 1, 7, 11, 13, 15 e 19 e suas duplicatas, em $\lambda 279,5 \mathrm{~nm}$. 

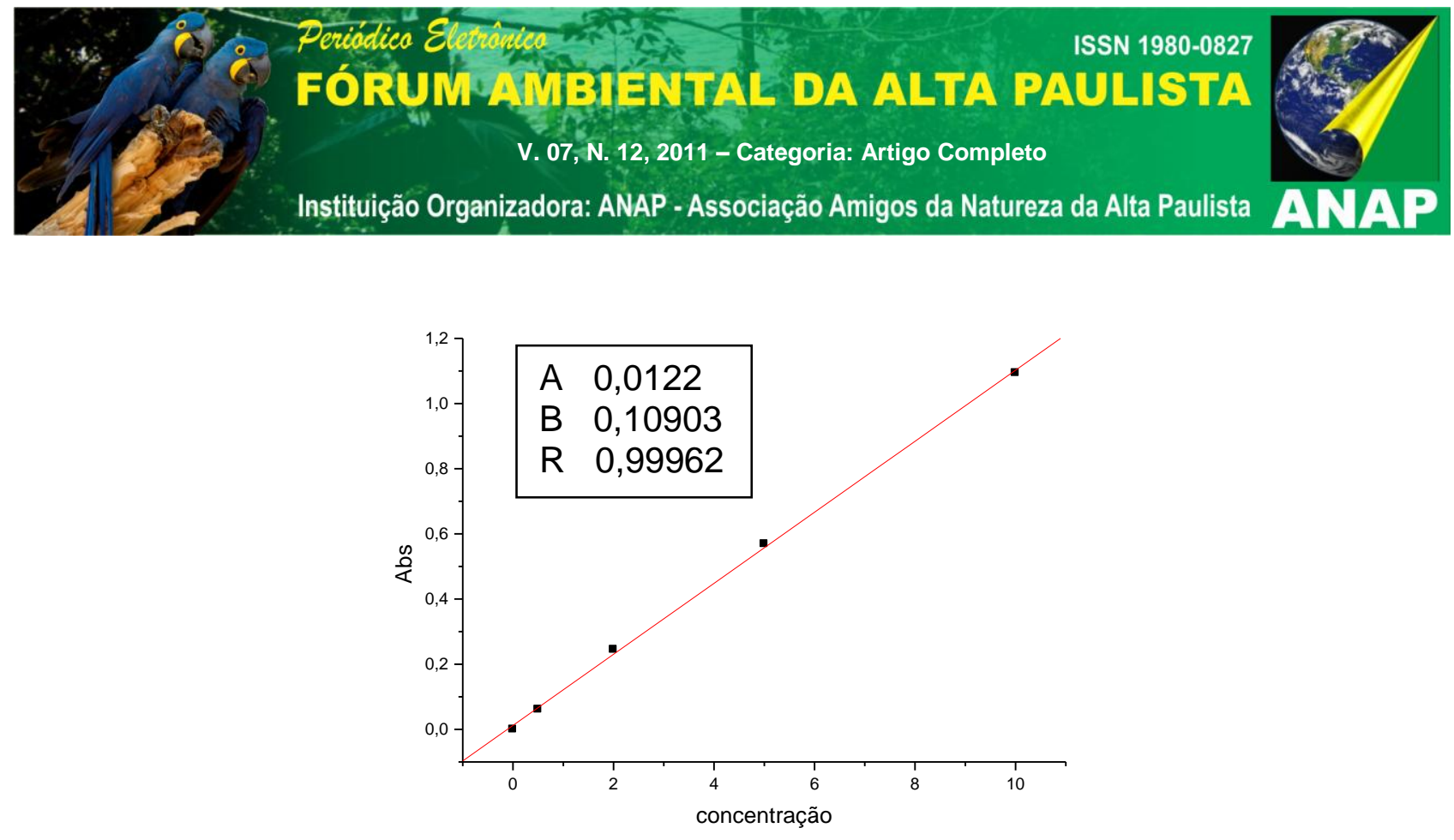

Figura 2. Curva-padrão utilizada para as seguintes amostras: laranja e cana-de-açúcar: 1, $2,3,4,5$ e suas duplicatas, em $\lambda 279,5 \mathrm{~nm}$.

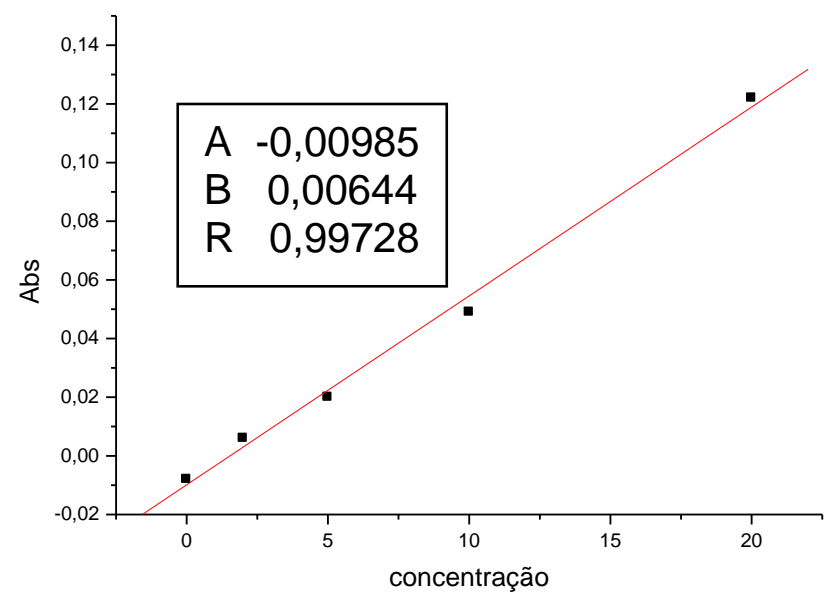

Figura 3. Curva-padrão utilizada para as seguintes amostras: 3, 5, 9, 17 e suas duplicatas e cana: 1 e 1', em $\lambda 403,1 \mathrm{~nm}$. 

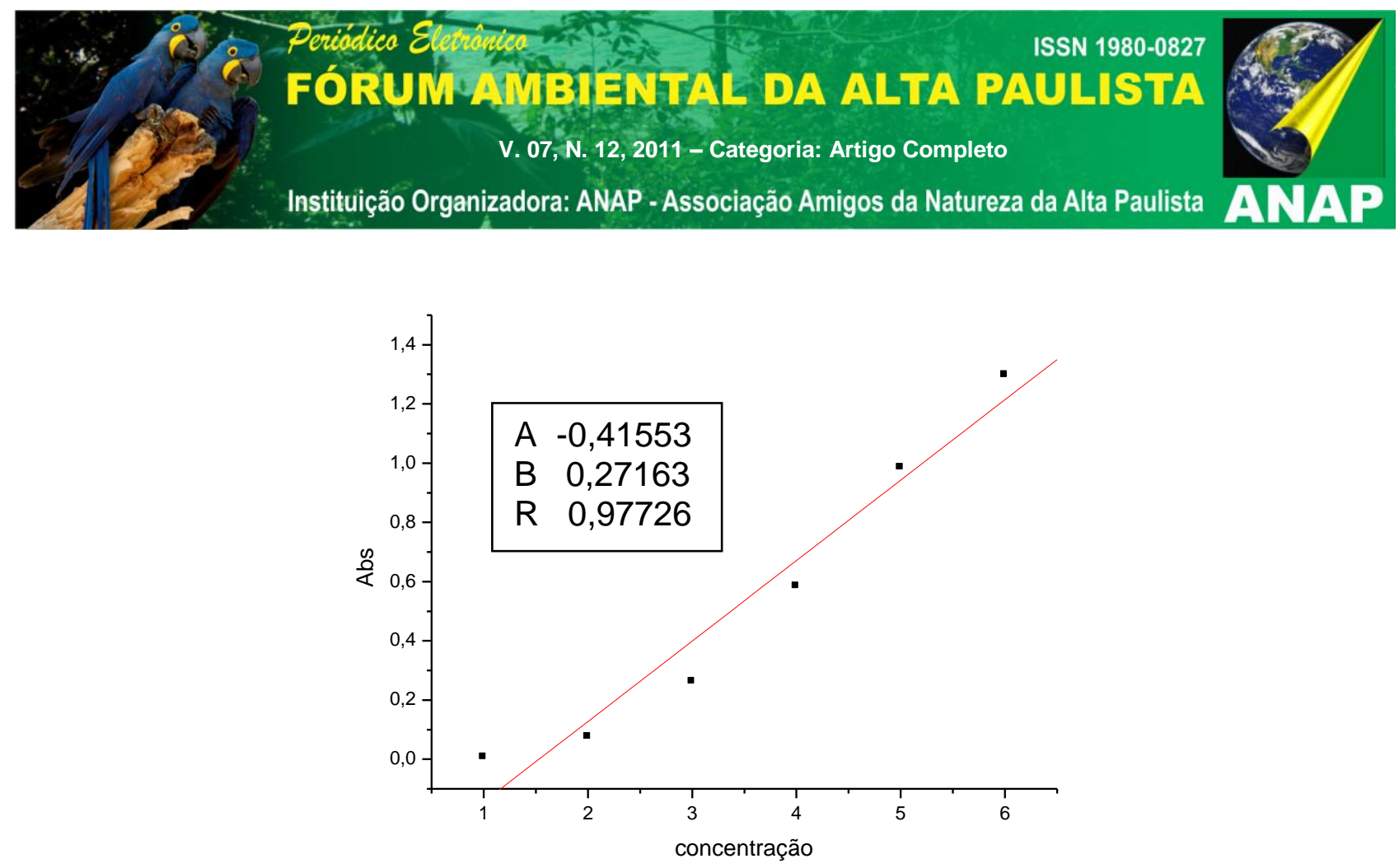

Figura 4. Curva-padrão utilizada para as seguintes amostras: $1 \mathrm{~N}$ a $14 \mathrm{~N}, 2 \mathrm{~F}, 4 \mathrm{~F}, 6 \mathrm{~F}, 8 \mathrm{~F}$, $10 \mathrm{~F}, 12 \mathrm{~F}, 14 \mathrm{~F}, 16 \mathrm{~F}, 18 \mathrm{~F}$ e $20 \mathrm{~F}$, em $\lambda=279,5 \mathrm{~nm}$.

Os valores das concentrações obtidas para o manganês solúvel em DTPA-TEA das amostras apresentadas pelas Figuras 1, 2 e 3 se encontram no Quadro 1.

\begin{tabular}{|c|c|}
\hline Amostra (solo estéril) & $\mathrm{mg} / \mathrm{L}$ \\
\hline 1 & 0,86 \\
\hline 3 & 12,63 \\
\hline 5 & 23,89 \\
\hline 7 & 5,86 \\
\hline 9 & 26,76 \\
\hline 11 & 1,38 \\
\hline 13 & 3,27 \\
\hline 15 & 5,77 \\
\hline 17 & 14,42 \\
\hline 19 & 1,22 \\
\hline Amostra (solo cultivado) & $\mathrm{mg} / \mathrm{L}$ \\
\hline 1 (laranja) & 3,81 \\
\hline 2 (laranja) & 5,54 \\
\hline 3 (laranja) & 3,87 \\
\hline 4 (laranja) & 3,18 \\
\hline 5 (laranja) & 2,42 \\
\hline 1 (cana-de-açúcar) & 10,69 \\
\hline 2 (cana-de-açúcar) & 3,87 \\
\hline 3 (cana-de-açúcar) & 3,87 \\
\hline 4 (cana-de-açúcar) & 5,91 \\
\hline
\end{tabular}




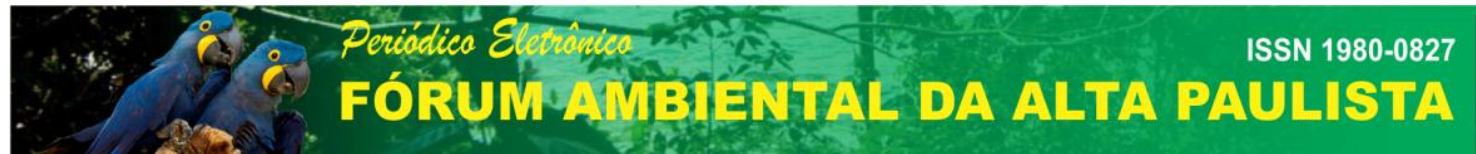

V. 07, N. 12, 2011 - Categoria: Artigo Completo

Instituição Organizadora: ANAP - Associação Amigos da Natureza da Alta Paulista

\begin{tabular}{|c|c|}
\hline 5 (cana-de-açúcar) & 4,41 \\
\hline
\end{tabular}

Quadro 1. Amostras de solos analisadas e os valores obtidos de concentração de manganês referentes às Figuras 1, 2 e 3.

Os valores das concentrações obtidas para o manganês solúvel em DTPA-TEA das amostras apresentadas pela Figuras 4 se encontram no Quadro 2.

\begin{tabular}{|c|c|}
\hline Amostras & Concentração (mg/L) \\
\hline $1 \mathrm{~N}$ & 4,323 \\
\hline $2 \mathrm{~N}$ & 3,662 \\
\hline $3 \mathrm{~N}$ & 5,875 \\
\hline $4 \mathrm{~N}$ & 4,434 \\
\hline $5 \mathrm{~N}$ & 2,364 \\
\hline $6 \mathrm{~N}$ & 2,669 \\
\hline $7 \mathrm{~N}$ & 2,684 \\
\hline $8 \mathrm{~N}$ & 4,625 \\
\hline $9 \mathrm{~N}$ & 5,397 \\
\hline $10 \mathrm{~N}$ & 4,930 \\
\hline $11 \mathrm{~N}$ & 5,357 \\
\hline $12 \mathrm{~N}$ & 6,500 \\
\hline $13 \mathrm{~N}$ & 2,772 \\
\hline $14 \mathrm{~N}$ & 6,353 \\
\hline $2 \mathrm{~F}$ & 5,783 \\
\hline $4 \mathrm{~F}$ & 4,728 \\
\hline $6 \mathrm{~F}$ & 2,073 \\
\hline $8 \mathrm{~F}$ & 5,651 \\
\hline $10 \mathrm{~F}$ & 4,845 \\
\hline $12 \mathrm{~F}$ & 5,441 \\
\hline $14 \mathrm{~F}$ & 4,239 \\
\hline $16 \mathrm{~F}$ & 3,437 \\
\hline $18 \mathrm{~F}$ & 1,632 \\
\hline $20 \mathrm{~F}$ & 3,084 \\
\hline &
\end{tabular}

Quadro 2. Amostras de solos analisadas e valores obtidos de concentrações de manganês referentes à Figura 4 .

Pode-se observar que cerca de $41 \%$ das amostras de solos apresentaram teores acima do patamar de $5,0 \mathrm{mg} / \mathrm{L}$, limite utilizado pelo governo do Estado de São Paulo (Quadro 3) para alto teor de manganês.

\begin{tabular}{|c|c|}
\hline Teor & $\mathrm{Mn}-($ DTPA $) \mathrm{mg} / \mathrm{dm}^{3}$ \\
\hline
\end{tabular}




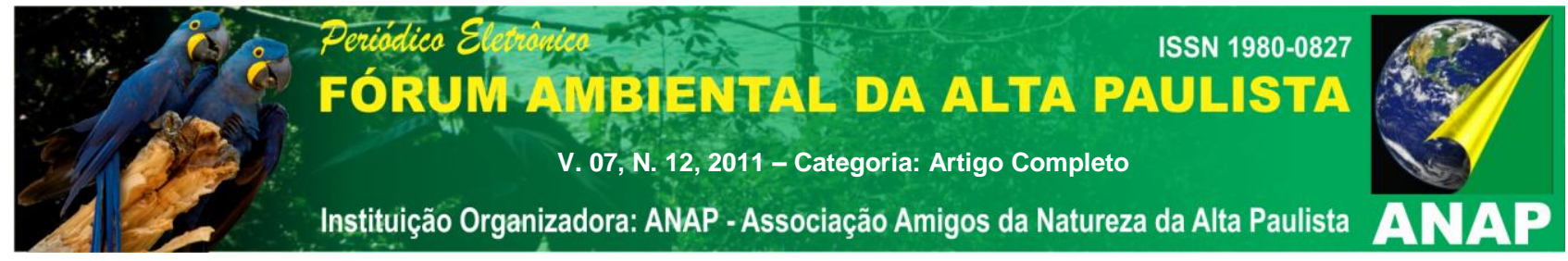

\begin{tabular}{|c|c|}
\hline baixo & $0-1,2$ \\
\hline médio & $1,3-5,0$ \\
\hline alto & $>5,0$ \\
\hline
\end{tabular}

Quadro 3. Valores orientadores para manganês no solo para o Governo do Estado de São Paulo (modificada).

Dessas amostras, cinco apresentaram teores de manganês de duas a cinco vezes superiores ao limite considerado como alto.

Com relação às amostras de solos cultivados com laranja e/ou cana-de-açúcar, três dentre dez revelaram teores acima do patamar alto. Nesse caso, muito possivelmente, esses valores se devem ao emprego de praguicidas e/ou fertilizantes, nos quais o manganês é constituinte comum.

Quanto às amostras de solos isentos de culturas, quatorze dentre trinta apresentaram altos teores do metal e, dentre essas, encontram-se as que apresentaram os maiores valores de concentração do estudo realizado.

Nesse caso, devido á ausência de siderúrgicas na região, que seria a principal razão e fonte de dispersão de manganês para a atmosfera com conseqüente acúmulo no solo após a precipitação das partículas, resta a hipótese de que esse excesso de manganês deve provir da liberação de produtos de combustão e/ou na forma de aditivos aos combustíveis.

Levantam-se as questões de quanto desse manganês é carreado por água e conduzido até mananciais superficiais e quanto do mesmo é levado aos aqüíferos por percolação, uma vez que não existem estudos dessa natureza.

\subsection{CONCLUSÃO}

Apesar de o manganês ser um elemento de vital importância, é certo que o seu excesso pode provocar alterações que levam a enfermidades nos seres humanos.

Infelizmente, estudos sobre esse tópico são muito raros. Raros, também, são os trabalhos sobre a concentração do metal no solo, nas águas (superficiais e profundas) e nas plantas. 


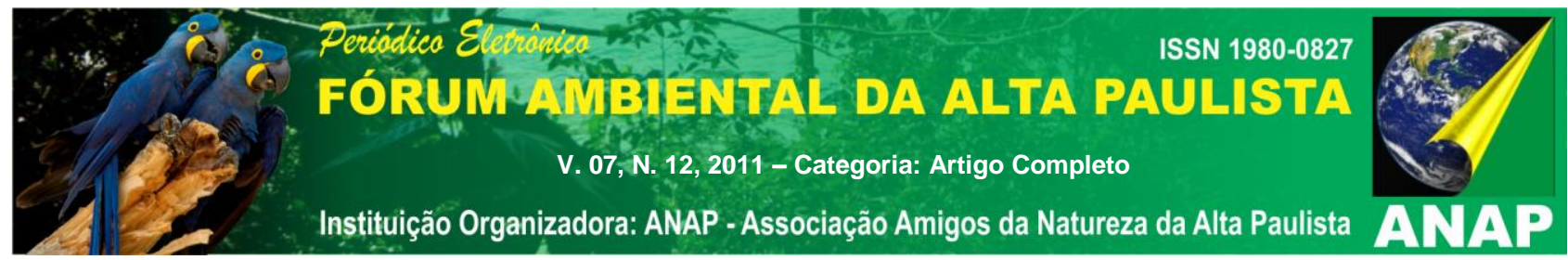

Deve-se a Menezes Filho, citado na introdução desse estudo, um interessante trabalho sobre o efeito do excesso de manganês, especialmente, em crianças e mães de uma comunidade próxima a uma siderúrgica na Bahia, fonte de emissão do metal para a atmosfera. Os dados obtidos foram comparados com os de uma população controle, distante vários quilômetros da siderúrgica. Baseando-se no fato de que o manganês tem um tropismo por tecidos ricos em melanina como o cabelo, principalmente os escuros, retina, conjuntiva pigmentada, pele escura e o cérebro, aquele autor coletou amostras de cabelo para determinação do mesmo, sangue para hemograma e amostras para exame parasitológico de fezes. Foram também coletadas amostras ambientais como água bruta e tratada, material particulado na fração respirável $\left(\mathrm{PM}_{2.5}\right)$ e poeira domiciliar.

Os resultados das amostras ambientais mostraram que os teores de Mn na água estavam dentro dos padrões aceitáveis, a concentração de $\mathrm{Mn}$ no ar $\left(\mathrm{PM}_{2.5}\right)$ estava em média três vezes superior a concentração referência da EPA (RfC $0,05 \mu \mathrm{g} / \mathrm{m}^{3}$ ) e os níveis de $\mathrm{Mn}$ na poeira domiciliar estavam aproximadamente 20 vezes mais elevados do que os níveis deste na poeira em residências do grupo controle. Os níveis de manganês no sangue estavam, na maioria, dentro dos valores normais (4-14 $\mathrm{gg} / \mathrm{L})$. Os níveis do metal no cabelo tiveram mediana de $9,70 \mu \mathrm{g} / \mathrm{g}(1,10-95,50) \mu \mathrm{g} / \mathrm{g}$ e 6,51 $\mu \mathrm{g} / \mathrm{g}(0,10-76,78 \mu \mathrm{g} / \mathrm{g})$, respectivamente, superando em muitas vezes a mediana encontrada na população controle 1,09 $\mu \mathrm{g} / \mathrm{g}(0,30-5,58 \mu \mathrm{g} / \mathrm{g})$. Os níveis de $\mathrm{Mn}$ no cabelo materno encontravam-se igualmente elevados $4,04 \mu \mathrm{g} / \mathrm{g}(0,10-77,75 \mu \mathrm{g} / \mathrm{g})$. O resultado desse excesso tem influenciado o desenvolvimento fetal e, também, tem proporcionado déficit intelectual nas crianças da comunidade.

O estudo de Menezes Filho lança mais uma questão sobre a forma de absorção do manganês que é a quantidade particulada presente no ar. Mais um dado sobre o qual não se tem parâmetros.

Guardadas as devidas proporções (no caso, severa emissão do metal por indústria metalúrgica na Bahia), acredita-se que é necessária, também, a quantificação do manganês presente no ar, no solo, nas águas e nas culturas nas demais regiões, em especial, naquelas de grandes concentrações urbanas e de veículos, pois não se sabe se esse metal tem sido liberado em quantidade muito elevada e tem sido absorvido de forma excessiva por nosso organismo durante anos. É necessário, também, avaliar-se se a 


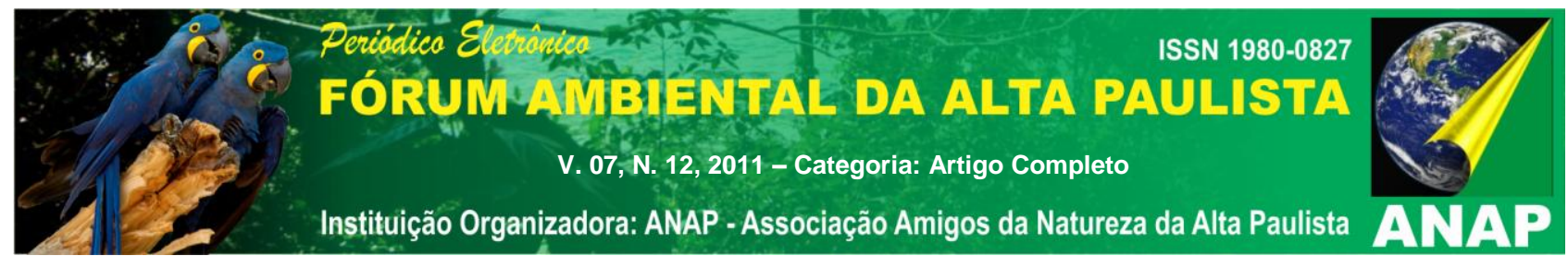

retenção do mesmo não é responsável pelo aumento de patologias e disfunções, principalmente, as neurotóxicas.

Cabe salientar que o método utilizado no desenvolvimento desse trabalho quantificou, somente, a forma mais disponível do manganês de maneira que, é de se esperar, que esse teor seja bem maior quando determinado em meio ácido. Nesse caso, uma maior quantidade do metal pode ser assimilada pelas plantas ou carreada para os mananciais, por águas de chuvas, principalmente, em momentos de chuvas mais ácidas.

\section{REFERÊNCIAS}

(ATSDR) Agency for Toxic Substances and Disease Registry. Division of Toxicology and Environmental Medicine. Disponível em: <http://www.atsdr.cdc.gov/es/phs/es_phs5.html>. Acesso em maio de 2011.

CAMARGO, O. A.; MONIZ, A. C.; JORGE, J. A. \& VALADARES, J. M. A. S. Métodos de Analise Química, Mineralógica e Física de Solos do Instituto Agronômico de Campinas. Campinas, Instituto Agronômico, 2009. 77 p. (Boletim técnico, 106, Edição revista e atualizada).

DAMIÃO, A. \& RAMOS, A. Manganês. Trabalho realizado no âmbito da disciplina de Toxicologia e Análises Toxicológicas I no ano letivo 2004/05. Faculdade de Farmácia da Universidade do Porto, Portugal. Disponível em: http://www.ff.up.pt/toxicologia/monografias/ano0405/manganes/manganes.htm. Acesso em junho de 2011.

GOVERNO DO ESTADO DE SÃO PAULO. Disponível em: D:AArquivos/Documentoslartigos e outros sobre soloslinterpretação análise de solo gov SP.htm. Acesso em maio de 2011.

MANZINI, F. F.; SÁ, K. B. \& PLICAS, L. M. A. Metais pesados: fonte e ação toxicológica. In: FÓRUM AMBIENTAL DA ALTA PAULISTA, 6. Tupã, 2010. Periódico Eletrônico, p. 800-815, 2010.

MENEZES FILHO, J. A. Níveis elevados de manganês e déficit cognitivo em crianças residentes nas proximidades de uma metalúrgica ferro-manganês na Região Metropolitana de Salvador, Bahia. Rio de Janeiro, 2009. 148p. Tese (Doutorado em Ciências na área de Saúde Pública e Meio Ambiente). Escola Nacional de Saúde Pública Sérgio Arouca.

SILVA, F. C. Manual de análises químicas de solos, plantas e fertilizantes. Embrapa Solos (Rio de Janeiro)/Embrapa Informática Agropecuária (Campinas), 1999, 370p. 